\title{
Selective Blockade of the Antigen-Receptor-Mediated Pathway of T Cell Activation in Patients with Impaired Primary Immune Responses
}

\author{
Stefan C. Meuer, ${ }^{\star}$ Martina Hauer, ${ }^{\ddagger}$ Peter Kurz, ${ }^{\ddagger}$ Karl-Hermann Meyer zum Büschenfelde, ${ }^{*}$ and Hans Köhler \\ ${ }^{*}$ Division of Applied Immunology, German Cancer Research Center (DKFZ) D-6900 Heidelberg, FRG; ${ }^{\ddagger}$ I. Medizinische Klinik und \\ Poliklinik, Johannes Gutenberg Universität, D-6500 Mainz, Federal Republic of Germany
}

\begin{abstract}
We investigated impaired cellular immune responses of individuals on chronic hemodialysis by using monoclonal antibodies that trigger differential pathways of $T$ cell activation. Reduced cellular reactivity, which exists in a high proportion of such patients, can be attributed to a failure of the monocyte population to support the process of primary $T$ cell activation in vitro. This defect results in a lack of interleukin 2 production, which is critically dependent on a monocyte-derived signal. In contrast, $T$ lymphocyte function was found to be physiologic. Perhaps more important, the degree of monocyte dysfunction in vitro correlated with the same patients' in vivo responses to hepatitis B vaccination. Addition of recombinant human interleukin 2 fully reconstituted their deficient immune response in vitro.
\end{abstract}

\section{Introduction}

Human $T$ lymphocytes can be activated through differential pathways to express their functional repertoires (1-5). Antigens in context with major histocompatibility complex determinants provide the first signal of the T3-Ti antigen receptormediated mode of $T$ cell triggering, which is, in addition, critically dependent on accessory cell help (6-8). In contrast, $T$ cell activation via the $T 11$ sheep erythrocyte receptor glycoprotein represents an antigen independent "alternative pathway" that circumvents a monocyte requirement $(5,8,9)$. Besides natural ligands for these two sets of surface receptors, monoclonal antibodies exist that are capable of exhibiting ligandlike agonistic effects $(3-5,10)$.

We investigated in vitro functions of peripheral blood mononuclear cells from individuals with deficient primary immune responses in vivo by employing such monoclonal antibodies (anti-T3, anti-T $11_{2}$, anti-T $11_{3}$ ) as stimuli. Immunodeficiency in these patients is secondary to chronic renal failure (11-19) and can be quantitated by means of the individual capacity to mount a primary immune response to hepatitis B vaccine. In this regard, controlled efficacy studies in the United States and Europe recently demonstrated that a high proportion of uremic patients fail to respond to otherwise highly immunogenic vaccines (20-27).

The studies reported below indicate that nonresponsiveness to hepatitis B vaccination in this group of individuals

\footnotetext{
Address reprint requests to Dr. Meuer.

Received for publication 3 July 1986 and in revised form 20 April 1987.
}

J. Clin. Invest.

(C) The American Society for Clinical Investigation, Inc. 0021-9738/87/09/0743/07 \$2.00

Volume 80, September 1987, 743-749 correlates with a blockade at a discrete step of the T3-Ti antigen receptor mediated mode of $\mathrm{T}$ cell activation, whereas the T11 pathway is unaffected.

\section{Methods}

\section{Patients}

The 23 patients investigated suffer from terminal renal insufficiency and are all on chronic hemodialysis. Patients are numbered (1-23) and their clinical characterization is as follows (age/sex/total time on hemodialysis (years)/dialysis time per week (hour)/disease):

1 (71/m/6/13/analgesic nephropathy)

2 (39/f/4/12/diabetic nephropathy)

3 (63/f/6/13/glomerulonephritis)

4 (50/m/5/12/analgesic nephropathy)

5 (37/f/4/10/nephrosclerosis)

6 (56/m/6/15/polycystic kidney disease)

7 (47/m/7/15/diabetic nephropathy)

8 (61/f/4/13/glomerulonephritis)

9 (55/f/1/13/polycystic kidney disease)

10 (49/f/10/15/glomerulonephritis)

$11(62 / \mathrm{m} / 13 / 13 /$ glomerulonephritis)

$12(53 / \mathrm{m} / 9 / 15 /$ glomerulonephritis)

$13(62 / \mathrm{m} / 7 / 15 /$ analgesic nephropathy)

14 (52/f/4/13/chronic pyelonephritis)

15 (59/m/6/13/amyloid nephropathy)

$16(49 / \mathrm{m} / 8 / 15 /$ diabetic nephropathy)

17 (58/f/4/13/polycystic kidney disease)

$18(68 / \mathrm{m} / 6 / 15 /$ hydronephrosis $)$

$19(24 / \mathrm{m} / 4 / 12 /$ Alport's syndrome)

$20(42 / \mathrm{m} / 6 / 15 /$ chronic pyelonephritis)

$21(42 / \mathrm{m} / 13 / 15 /$ renal tuberculosis $)$

22 (69/f/1/13/polycystic kidney disease)

23 (78/m/4/13/analgesic nephropathy).

Control subjects I-IV were healthy members of the medical staff (age 30-55; two males, two females). Liver enzymes in all individuals were normal and no hepatitis B markers were present.

\section{Hepatitis $B$ vaccination}

All uremic patients (1-23) had received two intramuscular injections of hepatitis B vaccine (40 $\mu \mathrm{g})$; (controls $20 \mu \mathrm{g}$ ) (Merck, Sharp and Dohme, GmbH, Darmstadt, FRG) at an interval of 4 wk and a third injection 6 mo later. When no anti-HBs-antibodies could be detected after $12 \mathrm{mo}$, a fourth vaccination was administered. If there was no seroconversion despite the fourth vaccination, a fifth injection followed 3 mo later.

Laboratory controls were carried out twice before the beginning of vaccination and afterwards at intervals of $0,1,2,3,4,5,6,7,8,9,12$, 18,21 , and 24 mo. HBsAg (Auszyme), anti-HBc (Corzyme), anti-HBs (Ausab), $\mathrm{HBeAg}$ and anti-HBe (Abbott-HBe) were determined with commercially available test systems (Abbott Laboratories, North Chicago, IL). Sera with positive anti-HBs findings were tested in double dilutions to the endpoint. The limiting value was considered 2.1 times to control determinations. The individual persons were rated as positive when the fourfold limiting value was exceeded. The following laboratory values were determined each time: serum glutamic oxalo- 
acetic acid transaminase, serum glutamic pyruvic transaminase, $\gamma$-glutamyl transferase, alkaline phosphate, total bilirubin, IgG, and IgM.

According to anti-HBsAg titers, patients were grouped as follows:

Responders $(R) .{ }^{1}$ Seroconversion occurred 12 mo after standard vaccination; anti-HBs positivity in two consecutive control patients $(13,16-24)$

Nonresponders (NR). At no time point was anti-HBs detectable (patients 1-7, 22, 23).

Weak responders $(W R$ ). Low titers following vaccination (between two and four times the negative control value); anti-HBs positivity in one of two consecutive controls (C); no seroconversion after standard vaccination (patients $8-12,14,15$ ).

\section{Derivation and characterization of lymphocyte populations} Heparinized blood was drawn always before the start of hemodialysis. Peripheral blood mononuclear cells (PBMC) were obtained by density gradient centrifugation using Ficoll-Paque (Pharmacia Fine Chemicals, Uppsala, Sweden).

PBMC of each individual were analyzed for their reactivity with monoclonal antibodies by means of indirect immunofluorescence on an EPICS-C cell sorter (Coulter Electronics, Hialeah, FL).

\section{Reactivities}

Anti-T3. All mature T cells: NR, 49.0\%-68.7\%; WR, 50.2-76.8\%; R, 51.4-74.1\%; C, 50.8-77.2\%.

T4/T8 ratios. Helper/suppressor ratios: NR, 1.6-3.1; WR, 1.5-3.0; R, 1.7-2.9; C, 1.4-2.6.

Anti-B1. Mature B lymphocytes: NR, 7.8-13.8\%; WR, 7.6-13.6\%; R, 6.4-11.0\%; C, 8.6-10.9\%.

Anti-Mo2. Monocyte specific: NR, 4.6-10.9\%; WR, 3.8-11.8\%; R, 4.7-10.4\%; C, 5.2-10.7\%.

None of these values is statistically significant. However, PBMC populations of all patients investigated here were within the normal range as determined on a large control collective in our clinical diagnostic laboratory.

\section{Purified T cells and monocytes}

Purified T cells were prepared by E-rosetting with sheep red blood cells. Subsequently, $\mathrm{E}^{+}$and $\mathrm{E}^{-}$were individually plated onto glass Petri dishes and incubated overnight at $37^{\circ} \mathrm{C}, 6 \% \mathrm{CO}_{2}$, humidified atmosphere in culture medium RPMI 1640 supplemented with $10 \%$ fetal bovine serum, $1 \%$ penicillin-streptomycin and $2 \%$ L-glutamine (Gibco Laboratories, Grand Island, NY).

To further deplete monocytes nonadherent $\mathrm{E}^{+}$cells were further incubated with monoclonal antibodies anti-I2 (28) and anti-Mo2 (29) (final dilution 1:200 ascites in medium) for $30 \mathrm{~min} 37^{\circ}$, then washed once and subsequently treated with preabsorbed rabbit serum as a source of complement for $60 \mathrm{~min} 37^{\circ} \mathrm{C}$ in a shaking water bath. After three washes cells were adjusted to $2 \times 10^{6}$ cells $/ \mathrm{ml}$ and incubated overnight in standard culture medium and employed as a source of purified resting $\mathrm{T}$ lymphocytes. Adherent $\mathrm{E}^{-}$cells, incubated onto glass Petri dishes for $48 \mathrm{~h}$ in culture medium were gently removed with a rubber policeman and employed as a source of monocytes.

Cell viability as determined by trypan blue exclusion was $90 \%$. Purified T cell preparations were reanalyzed for reactivity with antiT11 (T lineage specific) and anti-Mo2 (monocyte specific). Briefly, anti-T11 reactivity in all cases exceeded $96 \%$ and was $99 \%$ in 23 of the 27 individuals investigated. Anti-Mo2 reactivity was always in the range of the negative control.

\section{Lymphokines and mitogens}

Recombinant human interleukin 2 (rec Il-2) was a generous gift of Sandoz (Vienna, Austria). Phytohemagglutinin (PHA-P) was purchased from Wellcome Laboratories (Burgwedel, FRG).

1. Abbreviations used in this paper: C, control; IL-2, interleukin 2; NR, nonresponders; WR, weak responders.

\section{Monoclonal antibodies}

Monoclonal antibody anti-T3 $\left(\operatorname{IgG}_{1}\right)$ was purified from ascites employing Sepharose protein A (Pharmacia, Uppsala, Sweden) according to the method of Ey et al. (30). Subsequently, $3 \mathrm{mg}$ of purified antibody were coupled to $1 \mathrm{ml}$ of swollen $\mathrm{CnBr}$-activated Sepharose beads (Pharmacia) (3). Anti-T $11_{2}$ and anti-T $11_{3}$ were produced and characterized as previously described (5) and employed in ascites form. AntiMo2 (29) and anti-12 (28) were generous gifts of Dr. R. Todd and Dr. L. M. Nadler, respectively (Dana Faber Cancer Institute, Boston, MA). Other monoclonal antibodies were purchased from Coulter Electronics (Krefeld, FRG). All monoclonal antibodies were employed at predetermined saturating concentrations.

\section{Proliferative assays}

$1 \times 10^{5}$ responder cells were incubated in the presence or absence of $5 \%$ adherent cells $(6,000 \mathrm{rad}$ irradiated) in round bottomed microtiter wells (Costar, Cambridge, MA) in $200 \mu \mathrm{l}$ of final culture medium RPMI 1640, supplemented with 10\% fetal bovine serum (Gibco Laboratories, Paisley, Scotland), $1 \%$ penicillin-streptomycin $(10,000 \mathrm{U} / \mathrm{ml})$ and $2 \%$ L-glutamine ( $200 \mathrm{mM}$ ) (Gibco). After $3 \mathrm{~d}$ of in vitro culture, wells were individually pulsed with $1 \mu \mathrm{Ci}$ of $\left[{ }^{3} \mathrm{H}\right]$ thymidine for $16 \mathrm{~h}$ and mashed employing a Titertek cell harvester (Flow Laboratories, Meckenheim, FRG). $\left[{ }^{3} \mathrm{H}\right]$ Thymidine uptake was measured in a liquid scintillation spectrometer (Packard Instruments Co., Inc., Downers Grove, IL). All results are expressed as means of triplicate cultures.

The various stimuli (anti-T3-Sepharose, anti-T $11_{2}+$ anti-T1 $1_{3}$ and PHA-P) were employed at concentrations that mediated comparable levels of $\left[{ }^{3} \mathrm{H}\right]$ thymidine uptake when titered on healthy control individuals.

\section{Expression of IL-2 receptors}

$2 \times 10^{5} \mathrm{~T}$ cells/sample prepared and pretreated as described in Table 2 were incubated with $5 \mu \mathrm{l}$ of ${ }^{125} \mathrm{I}$-interleukin 2 (purchased from Amersham Laboratories, Buckinghamshire, England) $\left(\sim 1 \times 10^{6} \mathrm{cpm}\right)$ for 1 $h$ at $4^{\circ} \mathrm{C}$. Subsequently, individual samples were washed three times with cold medium. Prior to analysis in an LKB gamma-spectrometer, cells were transferred into fresh tubes. To distinguish specific from nonspecific IL-2 binding ${ }^{125} \mathrm{I}-\mathrm{IL}-2$ in the presence of an anti-IL-2 receptor antibody at saturating concentrations was investigated. It should be noted that due to the very limited numbers of cells that could be obtained from dialysis patients and the need to perform, in parallel, phenotypic, functional, and IL-2 binding studies it was not possible to perform extensive IL-2 binding experiments.

To investigate expression of the Tac antigen (IL-2 receptor) monoclonal antibody 1 HT4 4H3 (kindly provided by Dr. Ellis Reinherz, Dana Farber Cancer Institute, Boston, MA) was employed in saturating concentrations (ascites $1 / 1,000$ ). Samples were developed with goat anti-mouse Fab'2 FITC (Coulter) and analyzed on an EPICS C cell sorter.

It should be noted that the in vitro experiments were performed blindly, i.e., the clinical characterization of the various patients with regard to their in vivo immune responses (see above) were not known to the laboratory investigators. Not until all in vitro results had been obtained the comparison with in vivo responses to hepatitis B virus (HBV)-vaccination was performed. Moreover, the in vitro experiments were repeated under identical conditions from patients $4,5,10,13,19$, 23 , and the control individuals $\sim 2$ mo and again 9 mo after their initial characterization with reproducible results. Moreover, $17 \mathrm{mo}$ after the initial experiments were performed, $T$ cells and monocytes from donors 2,4 , and 17 and control II were investigated with regard to function and IL-2 receptor expression. The functional results were comparable with the original data collected (see Figs. 1 and 3). It is of interest to note that in the case of patient 18 , initially found to be a responder in vivo and in vitro, an in vitro NR situation was detected 17 mo later. Coincidentally, this patient turned anti-HBs negative and, several months later, $\mathrm{HBsAg}$ positive (carrier). 


\section{Results}

In the present study we have investigated 23 uremic patients on chronic hemodialysis and a group of healthy individuals with regard to cellular immune responses in vitro. All individuals had been vaccinated against hepatitis $B$ prior to the present analysis (21) and grouped according to their anti-HBs serum titers as, respectively, R, WR, and NR (see Methods).

Given this inability of the two latter groups to mount a physiologic primary immune response in vivo, we investigated how their $\mathrm{T}$ lymphocytes respond to an antigenlike stimulus (i.e., anti-T3 in Sepharose-linked form: S-anti-T3) (3). This monoclonal antibody is directed at a nonpolymorphic subunit of the human T3-Ti antigen receptor complex and can exhibit functional effects that are indistinguishable from those mediated by the natural ligand of T3-Ti, namely antigen itself. As shown in Table I, S-anti-T3 alone was not mitogenic for resting $\mathrm{T}$ lymphocytes. However, in the presence of $5 \%$ irradiated autologous monocytes, proliferation to S-anti-T3 could be detected. Perhaps more important, the levels of $\left[{ }^{3} \mathrm{H}\right]$ thymidine incorporation were found to be very distinct among the patients investigated. Thus, whereas patients 4 and 5, representative for a group of 7 NRs to vaccination mounted little if any responses, WR 13 and 10 had reduced but detectable responses and $\left[{ }^{3} \mathrm{H}\right]$ thymidine uptake of $\mathrm{T}$ lymphocytes from patients 19 and 23 appeared to be comparable to the healthy control individuals investigated (I, II). It should be noted that patient 19 was a vaccine responder, whereas patient 23 was a nonresponder. Additional but less pronounced differences among these patients existed regarding in vitro responses after PHA stimulation (Fig. 1).

Lymphocyte proliferation after antigen-like stimuli is known to be dependent on an efficient interaction between $T$ cells and monocytes (6-8). Therefore, we investigated whether impaired responses of dialysis patients to S-anti-T3 stimulation were due to a defect either at the level of $T$ lymphocytes or monocytes, or both. Thus, $\mathrm{T}$ cells from each patient were individually combined with monocytes (5\%) from a healthy individual and stimulated with S-anti-T3. As shown in Table I, fifth line, proliferative responses were obtained in all patients under these conditions. In contrast, no significant differences could be observed whether autologous or "healthy" irradiated

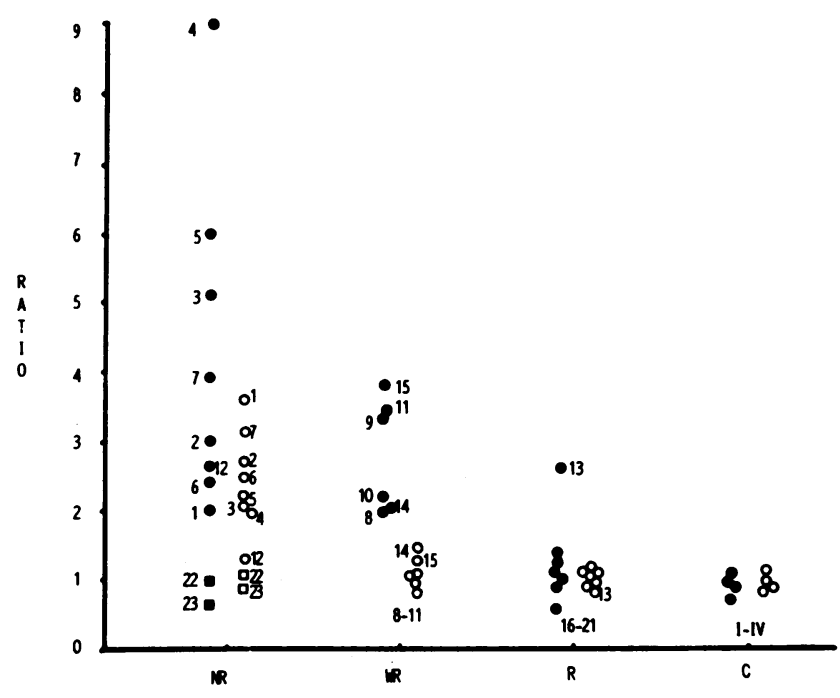

Figure 1. Ratios for anti-T3 stimulation (๑) and PHA-stimulation (0) of patients grouped according to their in vivo response after hepatitis B-vaccination. () PHA ratios and ( $\square$ ) anti-T3 ratios of two additional nonresponders; patients 1-23, controls I-IV. Ratios were calculated as follows: cpm [ $\left.{ }^{3} \mathrm{H}\right] \mathrm{TdR}$ uptake in the presence of "healthy" monocytes/cpm $\left[{ }^{3} \mathrm{H}\right] \mathrm{TdR}$ uptake in the presence of autologous monocytes.

monocytes were added to the $T$ cell population of healthy controls and uremic responders to vaccination (e.g., patient 19).

This result supports the view that impaired monocyte function may exist in a high proportion of uremic patients. In contrast, $T$ cell function appeared to be physiologic. To further substantiate the former point, purified $\mathrm{T}$ cells from a healthy control person were individually incubated with monocytes (5\%) from each uremic patient, and subjected to anti-T3 stimulation. As shown in Table $\dot{I}$, seventh line, monocytes from patients who failed to support $T$ cell blastogenesis in the autologous combination functioned much less well in supporting blastogenesis of "healthy" $\mathrm{T}$ lymphocytes than did monocytes from individuals with a normal response to anti-T3 stimulation.

Table I. In Vitro Reactivities of T Cells after Triggering with Sepharose-anti-T3

\begin{tabular}{|c|c|c|c|c|c|c|c|c|c|}
\hline Responder cells & Stimulus & Patient 4 & Patient 5 & $\begin{array}{l}\text { Patient } \\
13\end{array}$ & $\begin{array}{l}\text { Patient } \\
10\end{array}$ & $\begin{array}{l}\text { Patient } \\
19\end{array}$ & $\begin{array}{l}\text { Patient } \\
23\end{array}$ & $I^{*}$ & $\mathrm{II}^{*}$ \\
\hline T cells & Medium & $246^{\ddagger}$ & 624 & 707 & 544 & 481 & 374 & 320 & 916 \\
\hline $\mathrm{T}$ cells & S-anti-T3 & 332 & 290 & 1.030 & 640 & 1.572 & 910 & 933 & 1.211 \\
\hline$T_{\text {patient }}+\mathbf{M} \phi_{\text {patient }}$ & Medium & 379 & 622 & 756 & 243 & 55 & 289 & 789 & 245 \\
\hline $\mathrm{T}_{\text {patient }}+\mathbf{M} \phi_{\text {patient }}$ & S-anti-T3 & 1.569 & 2.214 & 6.963 & 8.304 & 23.731 & 15.123 & 15.123 & 23.855 \\
\hline $\mathbf{T}_{\text {patient }}+\mathbf{M} \phi_{\text {healthy }}$ & S-anti-T3 & 20.961 & 14.466 & 19.136 & 18.894 & 22.457 & 16.894 & 14.987 & 24.888 \\
\hline anti-T3-ratio & & 13.4 & 6.5 & 2.8 & 2.2 & 0.9 & 0.9 & 1.0 & 1.0 \\
\hline $\mathrm{T}_{\text {healthy }}+\mathbf{M} \phi_{\text {patient }}$ & S-anti-T3 & 8.307 & 6.055 & 12.194 & 13.794 & 25.337 & 30.000 & 15.123 & 24.888 \\
\hline
\end{tabular}

* In the case of healthy control individuals, autologous $\mathrm{T}$ cells and $\mathrm{M} \phi$ were recombined. ${ }^{\ddagger} \mathrm{cpm}^{3} \mathrm{H}$-thymidine incorporation (means of triplicate values; $\mathrm{SD} \leq 18 \%$ ). In vitro responses of $\mathrm{T}$ cells and monocytes of six representative patients and healthy control individuals. $10^{5}$ purified $\mathrm{T}$ lymphocytes/well (total volume $200 \mu \mathrm{l}$ ) were incubated alone or in the presence of 5\% irradiated monocytes (derived as indicated) for $72 \mathrm{~h}$ followed by a 16 -h pulse with $1 \mu \mathrm{Ci}$ of $\left[{ }^{3} \mathrm{H}\right]$ thymidine/well. Proliferation was determined by means of $\left[{ }^{3} \mathrm{H}\right]$ thymidine incorporation. Anti-T3 ratios were calculated as described in the legend to Fig. 1 . Note that when $\mathrm{T}$ cells and monocytes were derived from different individuals (lines 5 and 7$),\left[{ }^{3} \mathrm{H}\right]$ thymidine uptake of unstimulated cultures never exceeded $3.500 \mathrm{cpm}$ (not shown in the table). 
Clonal $\mathrm{T}$ cell expansion directed by antigen occurs by means of the IL-2 receptor system (31-35). It follows that a deficient proliferative response can be due to either impaired IL-2 receptor expression, reduced IL-2 production, or both. Given the relation of the T3-Ti antigen receptor to the IL-2 receptor (10), expression of functional IL-2 receptors on T cells can be determined by means of acquisition of IL-2 responsiveness after antigen-receptor stimulation. To investigate this point, purified populations of $T$ lymphocytes of the various patients were obtained and incubated in the presence or absence of S-anti-T3. The extent of in vitro proliferation to a constant dose of recombinant IL-2 (rIL-2) $(2 \mathrm{ng} / \mathrm{ml})$ was then taken as an indication for the capacity to express functional IL-2 receptor molecules. As shown in Fig. 2, the capacity of T cells to respond to IL-2 after this antigenlike stimulation was markedly enhanced in most patients with impaired responses to anti-T3 stimulation (compare Table I and Fig. 1) (NR and WR).

Given these very differing proliferative responses to a constant concentration of exogenous rIL-2 after $\mathrm{T}$ cell receptor triggering, it was necessary to investigate IL-2 receptor expression by $T$ lymphocytes from representative vaccine responders and nonresponders. To this end, purified $\mathrm{T}$ lymphocytes were obtained from patients 2 (NR), 4 (NR), 17 (R), and control II (R). Expression of IL-2 receptors was determined by means of binding of anti-IL-2 receptor antibody to the cell surface (Fig. 3 ) as well as binding of ${ }^{125}$ I-labeled IL-2 (Table II) at various time points. As demonstrated, a markedly enhanced expression of IL-2 receptors by NR T lymphocytes was detectable in both in vitro systems. This was particularly obvious when cells were investigated on day 3 after incubation with S-anti-T3 and low concentrations of rIL-2 $(2 \mathrm{ng} / \mathrm{ml})$ were noted.

To further exclude that reduced IL-2 production was indeed not due to a defect at the $\mathrm{T}$ cell level we investigated, in

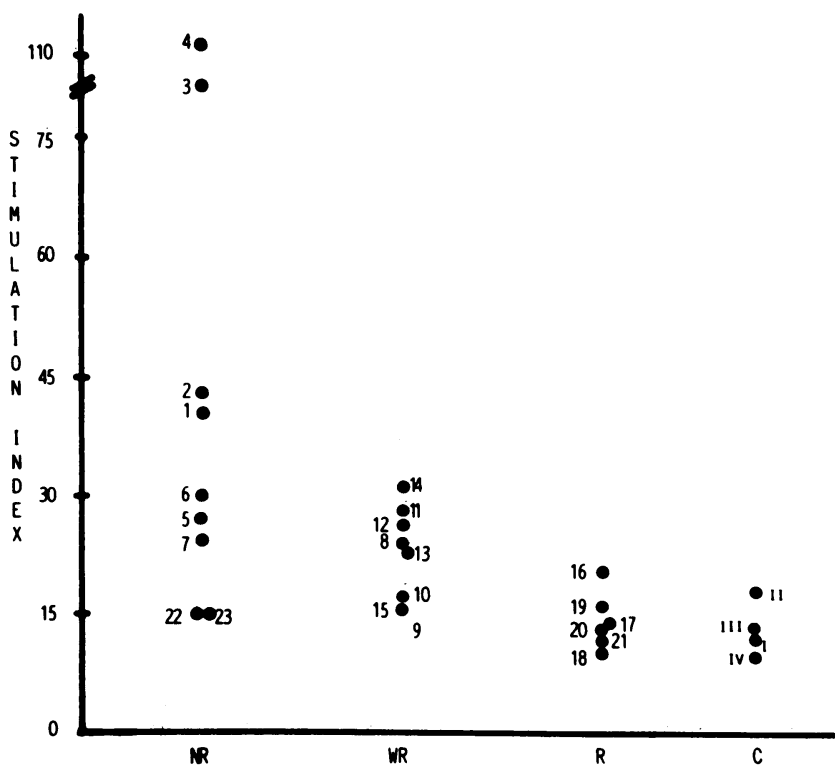

Figure 2. Acquisition of IL-2 responsiveness by purified T cells following antigen-receptor triggering with anti-T3-Sepharose. Results are expressed as stimulation index: $\mathrm{cpm}\left[{ }^{3} \mathrm{H}\right] \mathrm{TdR}$ uptake with $\mathrm{IL}-2$ $(2 \mathrm{ng} / \mathrm{ml})$ and anti-T3-Sepharose/cpm $\left[{ }^{3} \mathrm{H}\right] \mathrm{TdR}$ uptake with IL-2 alone.
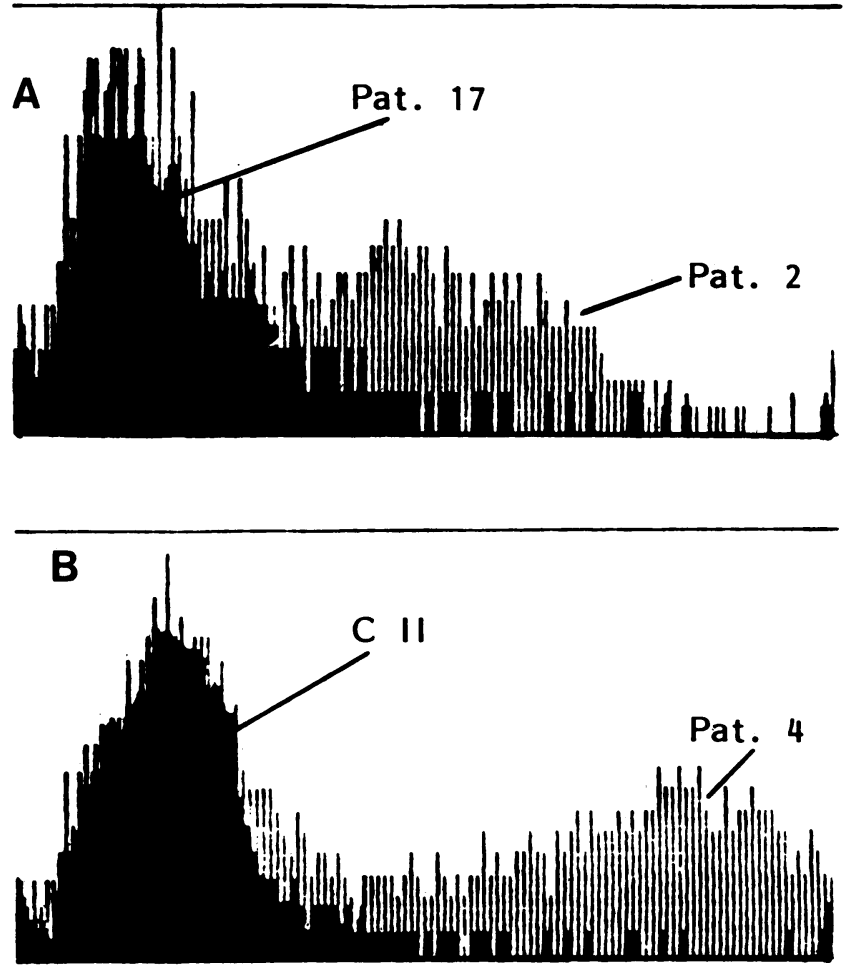

Figure 3. Surface binding of anti-IL-2 receptor antibody IHT4 4H3 by $\mathrm{T}$ lymphocytes from vaccine responders (patients 17 and C II) and nonresponders (patients 2 and 4). Purified T cells were incubated with Sepharose-anti-T3 and rIL-2 $(2 \mathrm{ng} / \mathrm{ml})$ for $3 \mathrm{~d}$ at $37^{\circ} \mathrm{C}, 7$ $\mathrm{CO}_{2}$ prior to analysis on an EPICS C cell sorter. Two histogram comparisons were performed employing an Immuno-Program (Coulter). (Under these experimental conditions, Tac expression on day 3 is rather low on $\mathrm{T}$ cells from healthy individuals. E.g., control II: day 0: 6.4\% above background, (a.b.); day 1: 5.1\% a.b.; day 3 (see Fig. 3, B): $11.9 \%$ a.b.

addition, the proliferative responses of $T$ lymphocytes to triggering via the "alternative pathway" of $T$ cell activation (5). Although this pathway is engaged via a $T$ cell antigen-receptor unrelated glycoprotein ( $\mathrm{T} 11$ ), proliferation is dependent on an intact IL-2/IL-2 receptor system as well. However, T11 triggering induces both IL-2 production and IL-2 receptor expression in the absence of monocyte help $(5,8)$. As shown in Fig. 4, "alternative pathway" triggering by monoclonal antibodies resulted in comparable levels of $\left[{ }^{3} \mathrm{H}\right]$ thymidine incorporation in all patients and control individuals tested.

Given that defective IL-2 production was most likely underlying nonresponsiveness to S-anti-T3, in a final set of experiments we investigated whether addition of recombinant human IL-2 was capable of circumventing this NR state. To this end, $T$ cells and autologous monocytes of each patient were incubated with S-anti-T3 and proliferation determined in the presence or absence of rIL-2. Table III gives representative experimental results of two nonresponders (patients 5 and 6 ) and one responder (patient 19). As shown, rIL-2 completely restored the deficient proliferative response, whereas addition of the same low concentration of rIL-2 in the case of the responder (patient 19), produced only a weak if any additional mitogenic effect. 
Table II. Binding of ${ }^{125} I-I L-2$ to $T$ Cells

from Nonresponders and Responders

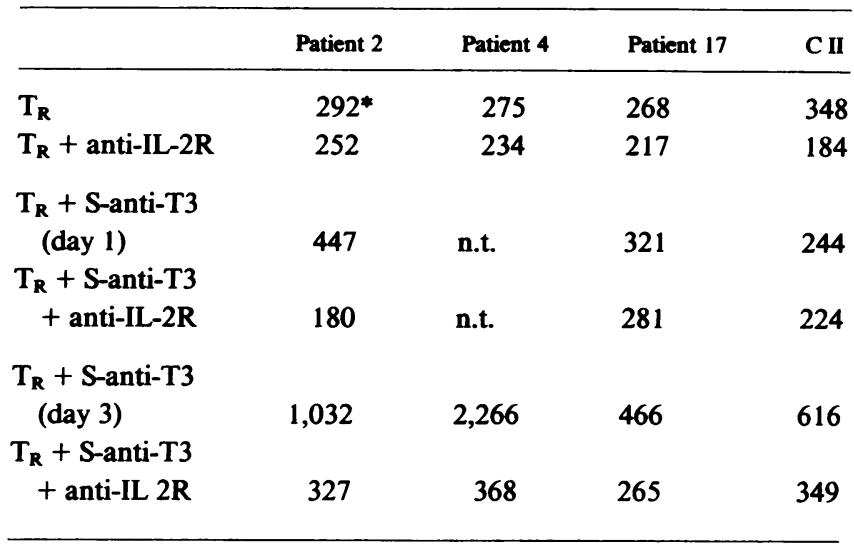

n.t. $=$ not tested

* $\mathrm{cpm}{ }^{125} \mathrm{I}-\mathrm{IL}-2 / 10^{5}$ cells

$\mathrm{T}$ cells were obtained and treated as described in Methods. Values represent means of duplicates (standard variation $<25 \%$ ). When the same type of analysis was performed employing cells of a human alloactivated $\mathrm{T}$ cell line, ( $>2 \mathrm{mo}$ in culture) the following values were obtained: Cells + ${ }^{125}$ I-IL-2: 3,191 cpm; Cells + anti-IL-2R + ${ }^{125} \mathrm{I}$-IL 2: $435 \mathrm{cpm}$. Although not shown, anti-T3 monoclonal antibody did not inhibit ${ }^{125} \mathrm{I}-\mathrm{IL}-2$ binding. The same cells were examined with regard to expression of the Tac-antigen by means of indirect immunofluorescence employing an anti-Tac monoclonal antibody. These results are demonstrated in Fig. 3. Note that these experiments were performed in the absence of monocytes (compare Fig. 2).

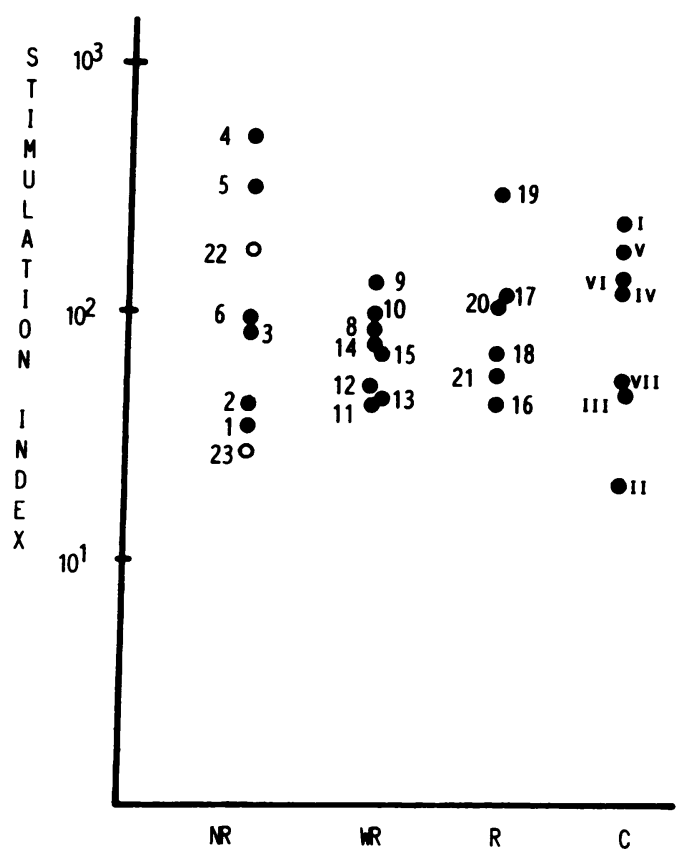

Figure 4. In vitro responses of purified patient $T$ cells after stimulation with anti- $\mathrm{T} 11_{2}$ and anti-T $11_{3}$. Results are expressed as stimulation index: cpm [ $\left.{ }^{3} \mathrm{H}\right] \mathrm{TdR}$ uptake of $\mathrm{T}$ cells plus anti-T $11_{2}+$ anti$\mathrm{T} 11_{3} / \mathrm{cpm}\left[{ }^{3} \mathrm{H}\right] \mathrm{TdR}$ uptake of $\mathrm{T}$ cells plus medium. The concentration of anti-T $11_{2}$ and anti-T $11_{3}$ employed mediated comparable amounts of $\left[{ }^{3} \mathrm{H}\right] \mathrm{TdR}$ uptake as PHA and anti-T3-Sepharose in the case of healthy individuals. Note that patient 7 was not tested in this experiment. Individuals V-VII are three additional controls.

\section{Discussion}

With the advent of monoclonal antibodies directed at unique $T$ cell differentiation antigens, new strategies to probe cellular immune responses have evolved. Unlike lectins, which mediate multiple and complex effects, monoclonal antibodies directed at defined $T$ cell surface structures and known to selectively inducing differential pathways of $T$ cell activation $(3,5)$ can now be employed as probes to define, in much greater detail, a given individual's cellular immune function. In the present study we have utilized mitogenic monoclonal antibodies directed at the, respectively, T3-Ti antigen recognition complex of human $T$ lymphocytes $(1-3,10)$ and the $T$ lineage specific T11 cell surface glycoprotein (5) in order to investigate the cellular basis of impaired immunologic responsiveness in patients undergoing chronic hemodialysis. Responses of the same patients to hepatitis B vaccination, as determined in a clinical vaccination trial (21), were utilized to judge the validity of the in vitro data obtained.

After activation of monocyte-reconstituted $T$ lymphocytes by S-anti-T3, a reagent that is known to mediate an antigenlike signal (3), a high proportion of patients with impaired responses to vaccination presented with deficient in vitro proliferation as compared to healthy control individuals and uremic vaccine responders (Table I, Fig. 1). This defect appeared, however, not to be due to abnormalities at the level of the $T$ cell but rather to a profound incapacity of such patients' monocytes to support the process of primary $T$ cell activation (Table I and Fig. 1). Perhaps more important, a striking correlation between monocyte dysfunction in vitro and the in vivo response to hepatitis vaccination was found. Thus, only 2 of the 27 individuals tested, namely patients 22 and 23 , were nonresponders to vaccination in spite of an apparently "normal" cellular immune function in vitro (Fig. 1, Table I). It should be noted that even among healthy individuals a nonresponder rate of $\sim 5 \%$ has been reported. This indicates that defects other than those investigated here can lead to nonresponsiveness after exposure to particular foreign antigens. However, at least with regard to immunodeficient uremic patients, deficient monocyte function is a likely explanation in the majority of cases.

In a previous study regarding cellular immune functions of uremic individuals deficient $T$ lymphocyte responses were observed (19). These experiments were performed employing unseparated $\mathrm{T}$ cells and monocytes and, therefore, as discussed, the reasons of reduced cellular proliferation and IL-2 production by $T$ lymphocytes remained unclear. Nevertheless, these earlier results are in line with the present data, which demonstrate reduced $\mathrm{T}$ cell activities as a consequence of monocyte failure.

One contribution of monocytes in the generation of a primary immune response is believed to be the secretion of IL-1. With this regard, a number of recent reports suggested that anti-T3 monoclonal antibodies plus IL-1 can synergize in inducing $T$ cell proliferation $(8,36-38)$. It is of interest to note that in preliminary studies addition of IL-1 to untreated as well as S-anti-T3 triggered $\mathrm{T}$ cells was not capable of substituting for "healthy" monocytes in vitro. This finding requires further extensive investigation but may indicate that monocyte function with regard to $T_{R}$ cell activation is not restricted to providing IL-1. 
Table III. Circumvention of Nonresponsiveness In Vitro by Addition of Human IL-2

\begin{tabular}{|c|c|c|c|c|c|}
\hline Responder cells & Stimulus & Additive & Patient 5 & Patient 6 & Patient 19 \\
\hline$T_{\text {patient }}+\mathbf{M} \phi_{\text {patient }}$ & Medium & Medium & $1.895^{*}$ & 1.192 & 1.419 \\
\hline $\mathbf{T}_{\text {petient }}+\mathbf{M} \phi_{\text {patient }}$ & S-anti-T3 & Medium & 2.214 & 4.898 & 23.731 \\
\hline $\mathrm{T}_{\text {patient }}+\mathbf{M} \phi_{\text {healthy }}$ & S-anti-T3 & Medium & 13.466 & 28.192 & 22.457 \\
\hline $\mathrm{T}_{\text {patient }}+\mathbf{M} \phi_{\text {patient }}$ & Medium & rIL-2 & 2.669 & 2.957 & 2.158 \\
\hline $\mathrm{T}_{\text {patient }}+\mathbf{M} \phi_{\text {patient }}$ & S-anti-T3 & rIL-2 & 27.345 & 36.089 & 29.523 \\
\hline
\end{tabular}

* $\mathrm{cpm}\left[{ }^{3} \mathrm{H}\right]$ thymidine incorporation (SD $\left.\leq 16 \%\right) \quad 10^{5}$ purified $\mathrm{T}$ lymphocytes were incubated with $5 \times 10^{3}$ irradiated monocytes and proliferation determined in the standard culture system (Methods). Recombinant human IL-2 (rIL-2) was employed at a final concentration of $2 \mathrm{ng} / \mathrm{ml}$. Analogous experiments were performed with T cells and monocytes from all 27 individuals (patients 1-23; control individuals I-IV) (see also Fig. 2). It should be noted that addition of autologous monocytes did never negatively influence $T$ cell responses to IL-2. Moreover, no differences were observed when unseparated PBMC and recombined purified T cells and monocytes were investigated in parallel.

Besides the finding that $\mathrm{T}$ cells from uremic nonresponders to vaccination reacted in a normal fashion to alternative pathway stimulation (Fig. 3), the expression of IL-2 receptors that critically determines the extent of clonal $\mathrm{T}$ cell expansion after an antigenic stimulus (10), occurred even stronger the more immunodeficient the respective patients presented in vitro and in vivo (Fig. 2, 3 and Table II). One explanation for this finding is that uremic patients indeed suffer from low levels of endogenous IL-2 and, therefore, a feedback mechanism that controls IL-2 receptor expression may not be functional in a physiologic fashion. This conclusion is supported by our recent finding that $T$ cells from uremic patients, when stimulated with mitogens or alloantigens, produce significantly less IL-2 (19). Given that monocytes are critically required for IL-2 production but not for IL-2 receptor expression in the course of primary immune responses (8), monocyte failure can explain the profound incapacity of elaborating sufficient amounts of IL-2 with the consequence of immunodeficiency in vivo. That addition of recombinant human IL-2 fully reconstituted the abnormal proliferative responses of nonresponder lymphocytes after antigen-receptor triggering provides further support for this view (Table II).

Most recently, we have investigated cellular immune functions of $9 \mathrm{HBsAg}$ carriers on hemodialysis. Interestingly, each single individual presented with parameters that appear to correlate with nonresponsiveness to vaccination as observed here (Fig. 1 and Fig. 2). In all cases, enhanced functional $\mathrm{T}$ cell responses to rIL-2 were accompanied by strong expression of the Tac antigen following $T$ cell receptor triggering and exposure to rIL-2 (compare Fig. 3). ${ }^{2}$

Given the enhanced sensitivity of such patients' IL-2 receptor system (Fig. 2 and 3), complete reconstitution was achieved with doses of IL-2 that, in the case of lymphocytes from healthy individuals, did not produce additional stimulatory effects (Table III). Moreover, these experiments may be taken as evidence for the notion that nonresponder monocytes do not actively inhibit $\mathrm{T}$ cell activation. Although not shown, identical data were obtained employing autologous serum supplements to the in vitro system, indicating that soluble inhibitory activities are likely not related to the observed immunodeficiency.

Therefore, based on the present analysis, addition of IL-2 during vaccination may represent a useful strategy to circum-

2. Meuer, S. C. Manuscript submitted for publication. vent the nonresponder state in vivo and perhaps improve on the overall immunodeficiency known to exist in patients with chronic renal failure.

\section{Acknowledgments}

Supported by the Deutsche Forschungsgemeinschaft (SFB 311/A3).

\section{References}

1. Meuer, S. C., K. A. Fitzgerald, R. E. Hussey, J. C. Hodgdon, S. F. Schlossmann, and E. L. Reinherz. 1983. Clonotypic surface structures involved in antigen specific human $\mathrm{T}$ cell function. Relationship to the T3 molecular complex. J. Exp. Med. 157:705-720.

2. Meuer, S. C., O. Acuto, R. E. Hussey, J. C. Hodgdon, K. A. Fitzgerald, S. F. Schlossman, and E. L. Reinherz. 1983. Evidence for the $\mathrm{T} 3$-associated $90 \mathrm{kD}$ heterodimer as the $\mathrm{T}$ cell antigen receptor. Nature (Lond.). 303:808-810.

3. Meuer, S. C., H. C. Hodgdon, R. E. Hussey, J. P. Protentis, S. F. Schlossman, and E. L. Reinherz. 1983. Antigen-like effects of monoclonal antibodies directed at receptors on human T cell clones. J. Exp. Med. 158:928-933.

4. Meuer, S. C., D. A. Cooper, J. C. Hodgdon, K. A. Fitzgerald, S. F. Schlossman, and E. L. Reinherz. 1983. Identification of the antigen/MHC receptor on human inducer T lymphocytes. Science (Wash. DC). 222:1239-1242.

5. Meuer, S. C., R. E. Hussey, M. Fabbi, D. Fox, O. Acuto, K. A. Fitzgerald, J. C. Hodgdon, J. P. Protentis, S. F. Schlossman, and E. L. Reinherz. 1984. An alternative pathway of $T$ cell activation: a functional role for the $50 \mathrm{kD}$ T11 sheep erythrocyte receptor protein. Cell. 36:897-906.

6. Palacios, R. 1985. Mechanisms by which accessory cells contribute in growth of resting T lymphocytes initiated by OKT3 antibody. Eur. J. Immunol. 15:645-651.

7. Schwab, R., M. K. Crow, C. Russo, and M. E. Weksler. 1985. Requirements for $\mathrm{T}$ cell activation by OKT3 monoclonal antibody: role of modulation of T3 molecules and Interleukin-1. J. Immunol. 135:1714-1717.

8. Meuer, S. C., and K. H. Meyer zum Büschenfelde. 1986. T cell receptor triggering induces responsiveness to Interleukin 1 and Interleukin 2 but does not lead to $\mathrm{T}$ cell proliferation. J. Immunol 136:4106-4112.

9. Hünig, T., G. Tiefenthaler, K. H. Meyer zum Büschenfelde, and S. C. Meuer. 1987. Alternative pathway activation of T cells by binding of CD2 to its cell surface ligand. Nature (Lond.). 326:298-301.

10. Meuer, S. C., R. E. Hussey, D. A. Cantrell, J. C. Hodgdon, S. F. Schlossman, K. A. Smith, and E. L. Reinherz. 1984. Triggering of the T3-Ti-antigen-receptor complex results in clonal $\mathrm{T}$ cell proliferation via an Interleukin 2 dependent autocrine pathway. Proc. Natl. Acad. Sci. USA. 81:1509-1513. 
11. Bramwell, S. P., J. D. Briggs, J. Stewart, M. A. Watson, D. Tsakiris, E. A. C. Follett, D. L. McWhinnie, D. H. Hamilton, and B. J. R. Junor. 1985. Dinitrochlorobenzene skin testing predicts response to hepatitis B vaccine in dialysis patients. Lancet. i:1412-1415.

12. Cappel, R., D. Van Beers, C. Liesnard, and M. Dratwa. 1983. Impaired humoral and cell-mediated immune responses in dialyzed patients after influenza vaccination. Nephron. 33:21-25.

13. Cosio, F. G., G. S. Giebink, C. Le Than, and G. Schiffman. 1981. Pneumococcal vaccination in patients with chronic renal disease and renal allograft recipients. Kidney Int. 20:254-258.

14. DeGast, G. C., B. Houwen, and G. K. Van der Hem. 1976. The TH.T-lymphocyte number and function and the course of hepatitis B in hemodialysis patients. Infect. Immun. 14:1138-1143.

15. Miller, T. E., and E. Stewart. 1980. Host immune status in uremia. I. Cell-mediated immune mechanisms. Clin. Exp. Immunol. 41:115-122.

16. Nakhla, L. S., and M. J. Goggin. 1973. Lymphocyte transformation in chronic renal failure. Immunology. 24:229-235.

17. Quadracci, L. J., O. Ringden, and M. Krzymanski. 1976. The effect of uremia and transplantation on lymphocyte subpopulations. Kidney Int. 10:179-184.

18. Stewart, E., and T. E. Miller. Host immune status in uraemia. 1980. II. Serum factors and lymphocyte transformation. Clin. Exp. Immunol. 41:123-129.

19. Kurz, P., H. Köhler, S. C. Meuer, TH. Hütteroth, and K. H. Meyer zum Büschenfelde. 1986. Impaired cellular immune responses in chronic renal failure: Evidence for a $\mathrm{T}$ cell defect. Kidney Int. 29:1209-1214

20. Crosnier, H., P. Jungers, A. M. Courouce, A. LaPlanche, E. Benhamou, F. Degos, B. Lacour, P. Prunet, Y. Cerisier, and P. Guesry. 1981. Randomised placebo-controlled trial of hepatitis B surface antigen vaccine in French haemodialysis units: II. Haemodialysis patients. Lancet. i:797-800.

21. Köhler, H., W. Arnold, G. Renschin, H. H. Dormeyer, and K. H. Meyer zum Büschenfelde. 1984. Active hepatitis B vaccination of dialysis patients and medical staff. Kidney Int. 25:124-128.

22. Cladd, E., M. D. Stevens, J. Harvey, M. D. Alter, P. E. Taylor, E. A. Zang, E. J. Harley, W. Szmuness, and the Dialysis Vaccine Trial Study Group. 1984. N. Engl. J. Med. 496-500.

23. Szmuness, W., C. E. Stevens, E. J. Harley, E. A. Zang, W. R. Oleszko, D. A. William, R. Sadovsky, J. M. Morrison, and A. Keller. 1980. Hepatitis B vaccine: demonstration of efficacy in a controlled clinical trial in a high-risk population in the United States. $N$. Engl. J. Med. 303:833-841.

24. Crosnier, J., P. Jungens, A. M. Courouce, A. Laplanche, E. Benhamou, F. Degos, B. Lacour, P. Prunet, Y. Ceresier, and P. Guery. 1981. Randomized placebo-controlled trial of hepatitis B surface antigen vaccine in French haemodialysis units. I. Medical staff. Lancet. i:455-459.
25. Francis, D. P., S. C. Hadler, S. E. Thompson, et al. 1982. The prevention of hepatitis B with vaccine: report of the Centers for Disease Control multi-center efficacy trial among homosexual men. Ann. Intern. Med. 97:362-366.

26. Szmuness, W., C. E. Stevens, E. J. Harley, et al. 1982. Hepatitis $B$ vaccine in medical staff of hemodialysis units: efficacy and subtype cross-protection. N. Engl. J. Med. 307:148-156.

27. Jilg, W., M. Schmidt, F. Deinhardt, and R. Zachoval. 1984. Hepatitis B vaccination: how long does protection last? Lancet. i:458 462.

28. Nadler, L. M., P. Stashenko, R. Hardy, J. M. Pesando, E. J. Yunis, and S. F. Schlossman. 1981. Monoclonal antibodies defining serologically distinct HLA-D/Dr related Ia-linked antigens in man. Hum. Immunol. 1:77-87.

29. Todd, R. F., L. M. Nadler, and S. F. Schlossman. 1981. Antigens on human monocyte identified by monoclonal antibodies. $J$. Immunol. 126:1435-1442.

30. Ey, P. L., S. J. Prowse, and C. R. Jenkin. 1978. Isolation of pure IgG1, IgG2 and IgG2b immunoglobulins from mouse serum using protein A-Sepharose. Immunochemistry. 15:429-440.

31. Smith, K. A., L. B. Lachmann, J. J. Oppenheim, and M. F. Favata. 1980. The functional relationship of the interleukins. J. Exp. Med. 151:1551-1556.

32. Smith, K. A., P. E. Baker, S. Gillis, and F. W. Ruscetti. 1980. Functional and molecular characteristics of $\mathrm{T}$ cell growth factor. $\mathrm{Mol}$. Immunol. 17:579-589.

33. Uchiyama, T., S. Broder, and T. A. Waldman. 1981. A monoclonal antibody (anti-Tac) reactive with activated and functionally mature human T cells. I. Production of anti-Tac monoclonal antibody and distribution of Tac (+) cells. J. Immunol. 126:1393-1397.

34. Leonard, W. J., J. M. Depper, T. Uchiyama, K. A. Smith, T. A. Waldmann, and W. C. Greene. 1982. A monoclonal antibody that appears to recognize the receptor for human $\mathrm{T}$ cell growth factor; partial characterization of the receptor. Nature (Lond.). 300:267-269.

35. Gootenberg, J. E., F. W. Ruscetti, J. W. Mier, A. Gazdar, and R. C. Gallo. 1981. Human cutaneous T cell lymphomas and leukemia cell lines produce and respond to T cell growth factor. J. Exp. Med. 154:1403-1418.

36. Manger, B., A. Weiss, C. Weyand, J. Goronzy, and J. D. Stobo. 1985. T cell activation: differences in the signals required for IL 2 production by nonactivated and activated $\mathrm{T}$ cells. $J$. Immunol 135:3669-3673.

37. Wakasugi, H., A. Harel, M. C. Dokhelar, D. Fradelizi, and T. Tursz. 1984. Accessory function and Interleukin 1 production by human leukemic cell lines. J. Immunol. 132:2939-2947.

38. Williams, J. M., D. Deloria, J. A. Hansen, C. A. Dinarello, R. Loertscher, H. M. Shapiro, and T. B. Strom. 1985. The events of primary $T$ cell activation can be staged by use of Sepharose-bound anti-T3 $(64,1)$ monoclonal antibody and purified Interleukin $1 . J$. Immunol. 135:2249-2255. 